\title{
ANALISIS PENERAPAN PENYUSUNAN LAPORAN KEUANGAN MASJID BAITUL MAKMUR SITUBONDO BERDASARKAN ISAK NO.35
}

\author{
Srirejeki Dwi Krismontiyah ${ }^{1 "}$, Yulinartati ${ }^{1}$, Nina Martiana ${ }^{1}$ \\ ${ }^{1}$ Universitas Muhammadiyah Jember, Jl. Karimata No. 49 Jember, Indonesia \\ "Korespondensi: srirejekidwikrismontiyah@gmail.com
}

\begin{abstract}
This study aims to analyze the preparation of the financial statements of the Baitul Makmur Situbondo Mosque based on ISAK No. 35. The type of research used is descriptive qualitative research. Data collection techniques were obtained through observation, interviews and documentation. The data obtained are secondary data and primary data. The results of this study indicate that the mosque's financial statements are not in accordance with ISAK No. 35. Then the mosque's financial statements were reconstructed in accordance with ISAK No. 35 by identifying transactions, making general journals, posting to the general ledger, making trial balances before adjustment, adjusting journals, trial balance after adjustment, preparing financial statements, closing journals, and the post-closing trial balance. And the final results of the accounting process are statements of financial position, statements of comprehensive income, reports of changes in net assets, statements of cash flows, and notes to financial statements.
\end{abstract}

Keywords: Non-profit, Mosque, ISAK No.35

\begin{abstract}
ABSTRAK
Penelitian ini bertujuan untuk menganalisis penyusunan laporan keuangan Masjid Baitul makmur Situbondo berdasarkan ISAK No.35. Jenis penelitian yang digunakan adalah penelitian kualitatif deskriptif. Teknik pengumpulan data diperoleh melalui observasi, wawancara dan dokumentasi. Data yang diperoleh yaitu data sekunder dan data primer. Hasil penelitian ini menunjukkan bahwa laporan keuangan masjid belum sesuai dengan ISAK No. 35. Maka laporan keuangan Masjid di rekontruksi sesuai dengan ISAK No.35 dengan mengidentifikasi transaksi, membuat jurnal umum, mem-posting ke buku besar, membuat neraca saldo sebelum penyesuaian, jurnal penyesuaian, neraca saldo setelah penyesuaian, penyusunan laporan keuangan, jurnal penutup, dan neraca saldo setelah penutupan. Dan hasil akhir dari proses akuntansi tersebut berupa laporan posisi keuangan, laporan penghasilan komprehensif, laporan perubahan aset neto, laporan arus kas, dan catatan atas laporan keuangan.
\end{abstract}

Kata kunci: Nirlaba, Masjid, ISAK No.35 


\section{PENDAHULUAN}

Masjid adalah sebuah organisasi nirlaba yang berfokus pada isu-isu (masalah) keagamaan. Tujuan Masjid bukanlah untuk mencari keuntungan dari aktivitasnya. Meskipun merupakan organisasi nirlaba, masjid tetap perlu menyiapkan laporan keuangan agar manajemen organisasi dapat mengukur sejauh mana manajemen organisasi telah memenuhi tanggung jawab para donatur untuk menyediakan sumber dana. Informasi yang disajikan dalam laporan keuangan juga dapat digunakan sebagai acuan dalam pengambilan keputusan ekonomi. Dengan menyiapkan laporan keuangan yang sesuai dan disajikan dengan benar, kepercayaan donatur akan meningkat dan keputusan tentang kebutuhan dan tujuan organisasi akan tetap fokus.

PSAK 45 telah diacu dalam pedoman pencatatan keuangan organisasi nirlaba, namun Dewan Standar Akuntansi Keuangan telah mencabut PSAK dengan menerbitkan PPSAK 13 yang mencakup pencabutan PSAK 45. Berdasarkan pertimbangan PSAK 45 International Financial Reporting Standards (IFRS), kantor akuntan publik mempertimbangkan dampak dari konvergensi International Financial Reporting Standards (IFRS). Dewan Standar Akuntansi Keuangan (DSAK) juga menyetujui ISAK 35 yang memuat penyajian laporan keuangan entitas nonprofit pada 11 April 2019, efektif untuk tahun buku yang dimulai pada 1 Januari 2020. Penyajian laporan keuangannya kini berpedoman pada ISAK 35.

Beberapa penelitian sebelumnya menunjukkan bahwa penyusunan dan penyajian laporan keuangan entitas nirlaba masih menggunakan cara manual yang tidak sesuai dengan ketentuan yang berlaku. Salah satunya adalah penelitian terhadap entitas nirlaba yang dilakukan oleh Eka Kusuma Dewi dan Muliyani pada tahun 2020. Hasil penelitian menunjukkan bahwa laporan keuangan yang disusun entitas tersebut sangat sederhana dan tidak sesuai dengan ketentuan yang berlaku.

Masjid Baitul Makmur Situbondo adalah sebuah mesjid yang terletak di Perumahan Panji Permai di Jalan Gunung Raung Situbondo. Laporan keuangan masjid Baitul Makmur disusun oleh bendahara masjid. Menyiapkan laporan keuangan setiap hari Jumat setiap minggu.

Menurut hasil pemeriksaan pengelola Masjid Baitul Makmur, pencatatan pengelolaan keuangan dibagi menjadi dua kategori, yaitu pemasukan dan pengeluaran kas. Salah satu sumber pendapatan pengurus masjid Baitul Makmur adalah pendapatan infaq. Infaq yang terkumpul (semua penerimaan dan pengeluaran kas) yang diterima bendahara akan dicatat. Biaya Masjid Baitul Makmur sudah termasuk transport khotib dan bilal serta pembayaran jasa tukang parkir. Selain itu, Masjid Baitul Makmur juga menyusun Laporan Keuangan Bulanan.

Namun, Masjid Baitul Makmur tidak menyusun Laporan Tahunan. Jadi, yang disusun hanya laporan Kas Infaq Mingguan dan Laporan Keuangan Bulanannya saja. Salah satu cara untuk menjadi organisasi yang dapat dipercaya masyarakat adalah dengan menghasilkan laporan keuangan yang akuntabel dan transparan sehingga para donatur dapat memahami kemana arah donasinya. Berdasarkan hasil pantauan, laporan keuangan bulanan Masjid Baitul Makmur tidak memenuhi standar.

Berdasarkan latar belakang yang telah diuraikan, peneliti ingin melakukan penelitian yang berjudul "Analisis Penerapan Penyusunan Laporan Keuangan Masjid Baitul Makmur Situbondo Berdasarkan ISAK No.35“. 


\section{METODE PENELITIAN}

\section{Desain Penelitian}

Metode yang digunakan dalam penelitian ini adalah metode kualitatif. Menurut Sugiyono, metode penelitian kualitatif adalah metode penelitian yang digunakan untuk meneliti kondisi objek alam. Munculnya metode ini disebabkan adanya pergeseran paradigma dalam persepsi tentang realitas, fenomena, atau fenomena, yang biasa dikenal dengan paradigma post-positivis. Metode ini dapat digunakan untuk mengumpulkan data yang mendalam, yaitu data-data penting yang dibutuhkan dalam penelitian.

Penelitian ini mencoba mendeskripsikan realitas alamiah bagaimana penerapan laporan keuangan entitas nirlaba Masjid Baitul Makmur dalam penyajian laporan keuangannya.Penelitian ini termasuk survei deskriptif. (Penelitian Kualitatif Deskriptif).

\section{Jenis Data}

Data penelitian diperoleh dari dua sumber, yaitu:

1. Data primer adalah sumber data yang diperoleh langsung oleh pengumpul data. Untuk memperoleh informasi dari tangan pertama, peneliti melakukan wawancara dan observasi langsung dengan pihak-pihak terkait yaitu ketua Masjid Takmir dan bendahara Masjid Baitul makmur.

2. Data sekunder adalah sumber data yang diperoleh secara tidak langsung oleh pengumpul data, seperti melalui dokumen. Penelitian ini memperoleh data bekas melalui buku, majalah dan website, serta didukung oleh data yang terkait dengan penelitian ini yaitu data keuangan atau pembukuan masjid Baitul Makmur tahun 2020.

\section{Teknik Pengumpulan Data}

Untuk memperoleh data yang diperlukan dalam penelitian, penulis menggunakan beberapa teknik, yaitu:

1. Observasi adalah pengamatan yang dilakukan dengan mencatat secara sistematis gejala-gejala yang diteliti (Usman dan Purnomo, 2004). Dalam penelitian ini, penulis menggunakan teknik observasi partisipatif untuk berpartisipasi aktif dalam objek penelitian atau berperan dalam kehidupan orang yang diamati. Penelitian dilakukan di Masjid Baitul Makmur, ketika organisasi (masjid) menerapkan buku harian bulanan dengan tujuan memahami cara mencatat laporan keuangan bulanan yang umumnya digunakan masjid. Peneliti juga melihat laporan keuangan yang disediakan oleh masjid untuk menentukan kelengkapan data yang diperlukan untuk melanjutkan penelitian.

2. Wawancara adalah percakapan lisan antara dua orang atau lebih dengan tujuan tertentu secara langsung. Dilakukan oleh seseorang yang membutuhkan data dan kemudian mengajukan pertanyaan. Penyedia data memberikan jawaban atas pertanyaan yang diajukan oleh interogator. Dalam penelitian ini, penulis mewawancarai beberapa pengurus masjid Baitul Makmur, khususnya takmir masjid dan bendahara masjid, untuk mendapatkan data utama yang mendukung penelitian.

3. Metode dokumentasi adalah metode pengumpulan data dengan cara merekam data yang ada. Data dapat dipulihkan melalui dokumen tertulis, gambar, dll. Teknik pencatatan yang digunakan dalam penelitian ini adalah dokumen yang dihasilkan dari Masjid Baitul Makmur berupa kegiatan organisasi, dokumen pelaporan keuangan berupa LPJ dan laporan bulanan, serta dokumen berdasarkan ISAK 35 dan penelitian pendukung lainnya. 


\section{Teknik Analisis Data}

Analisis data dalam penelitian ini menggunakan analisis deskriptif, dimana laporan keuangan Masjid Baitul Makmur disesuaikan dengan ISAK Nomor 35. Data yang dianalisis dengan tahapan - tahapan sebagai berikut:

1. Mengidentifikasi pos-pos laporan keuangan Masjid baitul Makmur yaitu diantaranya laporan posisi keuangan, laporan komprehensif, laporan aset neto, laporan arus kas, dan catatan atas laporan keuangan.

2. Melakukan analisa data dari hasil wawancara dan juga kombinasi dari hasil dokumentasi.

3. Menganalisis kesesuaian antara laporan keuangan Masjid Baitul Makmur dengan ISAK No.35.

4. Mengkontruksi laporan keuangan Masjid Baitul Makmur.

5. Mendeskripsikan penerapan ISAK No.35 dalam penyajian laporan keuangan pada Masjid Baitul Makmur.

\section{Peta Pemikiran}

Peta pemikiran merupakan metode untuk memaksimalkan peneliti untuk mengetahui isi pemikiran yang ada.

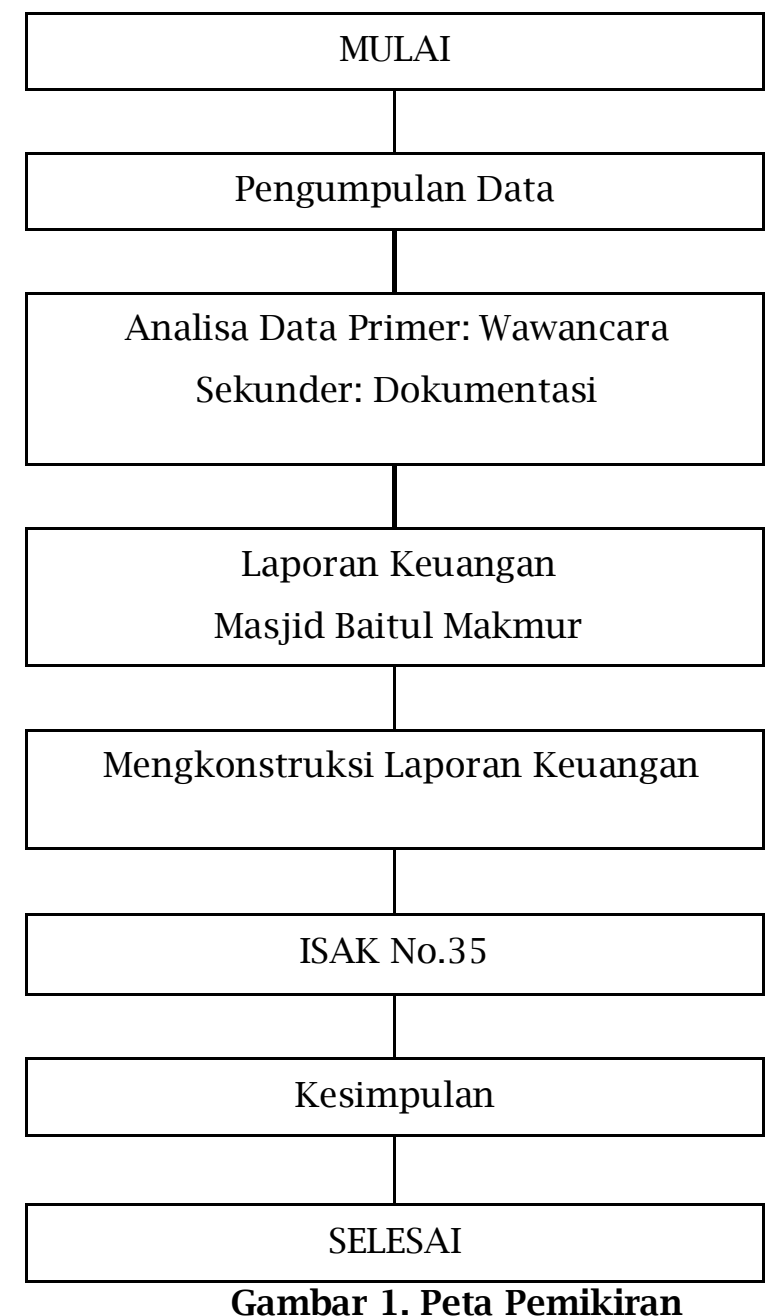

\section{HASIL DAN PEMBAHASAN}

\section{Profil Masjid Baitul Makmur}

Masjid Baitul Makmur dibangun pada tahun 1993 dan meliputi area seluas 2.300 meter persegi. Masjid Baitul Makmur didirikan sebagai tempat ibadah, dakwah, 
pendidikan dan kegiatan sosial. Masjid Baitul Makmur telah melaksanakan beberapa bidang kegiatan utama yaitu satuan pendidikan, masjid dan amal. Masjid Baitul Makmur juga rutin memperingati Hari Besar Islam (PHBI), seperti Tahun Baru Hijriah, Maulid Nabi, dan Malam Nuzulul Quran.

Kegiatan Masjid Baitul Makmur bertujuan untuk mewujudkan masyarakat yang cerdas dan peduli terhadap fakir miskin. Dari segi pendidikan, Masjid Baitul Makmur memberikan pendidikan dini kepada umat Islam di lingkungan sekitar seperti PAUD, RA, TPQ, dan MADIN. Masjid Baitul Makmur juga memberikan santunan berupa santunan kepada anak yatim dan dhuafa yang masih bersekolah.

\section{Menganalisis kesesuaian Laporan Keuangan menurut ISAK 35 dengan Laporan Keuangan Masjid Baitul Makmur}

Berdasarkan Laporan keuangan masjid Baitul Makmur masih sangat sederhana yaitu hanya penerimaan dan pembayaran tunai (cash), penerimaan dan pembayaran ini dilakukan melalui surat harian dengan bantuan komputer. Masjid Baitul Makmur hanya membuat laporan keuangan bulanan. Berikut adalah contoh salah satu Laporan Keuangan Bulanan Bulan Desember Tahun 2020 Masjid Baitul Makmur:

Tabel 1. Laporan Keuangan Desember 2020 Masjid Baitul Makmur Situbondo

\begin{tabular}{|c|c|c|}
\hline $\begin{array}{l}\text { Saldo Awal } 1 \text { Desember } 2020 \\
\text { Pemasukan }\end{array}$ & $\mathbf{R p}$ & 107.286.959 \\
\hline Infaq dari donatur & $\mathrm{Rp}$ & 1.000 .000 \\
\hline Infaq kotak amal kemasjidan & $\mathrm{Rp}$ & 15.342 .000 \\
\hline Infaq parkir jum'at & $\mathrm{Rp}$ & 213.800 \\
\hline TOTAL & Rp & 123.842 .759 \\
\hline Biaya Operasional & & \\
\hline Biaya Pengelola & $\mathrm{Rp}$ & 4.410 .000 \\
\hline Biaya Kantor \& Rumah Tangga & $\mathrm{Rp}$ & 838.500 \\
\hline Biaya Listrik, Air dan Telepon & $\mathrm{Rp}$ & 821.400 \\
\hline Biaya Peribadatan \& Dakwah & $\mathrm{Rp}$ & 1.200 .000 \\
\hline $\begin{array}{l}\text { Biaya Pemeliharaan \& } \\
\text { Kebersihan }\end{array}$ & $\mathrm{Rp}$ & 2.536 .000 \\
\hline TOTAL & Rp & 9.405 .900 \\
\hline Saldo Akhir & $\mathbf{R p}$ & 114.436 .859 \\
\hline
\end{tabular}

\section{Mengkontruksi laporan keuangan Masjid Baitul Makmur}

Setelah data diperoleh penulis, langkah selanjutnya penulis mencatat transaksi keuangan Masjid Baitul Makmur dengan mengidentifikasi transaksi yang terjadi, kemudian membuat jurnal umum, kemudian mempublikasikan atau memindahkannya ke buku besar, dan kemudian membuat neraca saldo, kemudian membuat jurnal penyesuaian, lalu neraca saldo disesuaikan, dan kemudian membuat laporan keuangan sesuai dengan ISAK 35 dan membuat jurnal penutup.

\section{Mendeskripsikan penerapan ISAK No.35 dalam penyajian laporan keuangan pada Masjid Baitul Makmur}

Setelah menyusun neraca saldo yang disesuaikan (adjusted balance), langkah selanjutnya adalah menyusun laporan keuangan Masjid Baitul Makmur sesuai dengan ISAK 35, antara lain laporan posisi keuangan, laporan laba rugi komprehensif, laporan perubahan aktiva bersih, laporan arus kas dan catatan atas laporan keuangan.

\section{Pembahasan}

Berdasarkan hasil dari penelitian diatas maka rekonstruksi laporan keuangan Masjid Baitul Makmur Situbondo berdasarkan ISAK No.35 adalah sebagai berikut: 


\section{Laporan Penghasilan Komprehensif}

Laporan laba rugi komprehensif adalah laporan yang terdiri dari akun pendapatan dan beban. Saldo akun pendapatan dan beban dalam laporan laba rugi komprehensif berasal dari neraca saldo yang disesuaikan. Saat disusun Laporan Pendapatan Komprehensif Masjid Baitul Makmur, pendapatan Masjid Baitul Makmur $\mathrm{Rp}$ 183.351.800 dan total biaya berkurang $\mathrm{Rp}$ 9.436.082.100. Total surplus atau defisit dalam laporan laba rugi komprehensif akan dimasukkan dalam laporan perubahan aset bersih. Berikut laporan hasil komprehensif Masjid Baitul Makmur.

Tabel 2. Laporan Penghasilan Komprehensif Masjid Baitul Makmur Tahun 2020

\section{TANPA PEMBATASAN DARI PEMBERI \\ SUMBER DAYA \\ Pendapatan \\ Pendapatan Infaq}

Total Pendapatan

Beban

Beban Pengelola

Beban Rumah Tangga

Beban Listrik, Air dan Telepon

Beban Peribadatan dan Dakwah

Beban Pemeliharaan dan Kebersihan

Beban Penyusutan Bangunan

Beban Penyusutan Peralatan

Beban Perlengkapan

Total Beban (catatan E)

Surplus (Defisit)

PENGHASILAN KOMPREHENSIF LAIN

TOTAL PENGHASILAN KOMPREHENSIF
$\mathrm{Rp} \quad 183.351 .800 \mathrm{Rp} \quad 183.351 .800$

$\begin{array}{lr}\mathrm{Rp} & (45.900 .000) \\ \mathrm{Rp} & (100,000) \\ \mathrm{Rp} & (745.650) \\ \mathrm{Rp} & (3.905 .000) \\ \mathrm{Rp} & (1.380 .000) \\ \mathrm{Rp} & (9.146 .250 .000) \\ \mathrm{Rp} & (237.480 .450) \\ \mathrm{Rp} & (321.000)\end{array}$

Rp (9.436.082.100)

Rp (9.252.730.300)

\section{Laporan Perubahan Aset Neto}

Laporan Perubahan Aktiva Bersih adalah pernyataan yang mencantumkan aktiva bersih yang dibatasi atau tidak dibatasi pada awal periode, kenaikan atau penurunan pada periode berjalan, dan saldo akhir. Pada laporan perubahan aktiva bersih, saldo awal sebesar Rp 43.733.673.959 diperoleh dari neraca saldo disesuaikan jumlah aktiva bersih tidak terikat, dan surplus (defisit) tahun berjalan adalah Rp 9.252.730.300 dari laporan laba rugi komprehensif, dan saldo akhir adalah Rp 34.480.943.659 dari total aset bersih. 
Berikut laporan perubahan aktiva bersih (aset neto) Masjid Baitul Makmur:

Tabel 3. Laporan Perubahan Aset Neto Masjid Baitul Makmur Tahun 2020

\begin{tabular}{|c|c|}
\hline \multicolumn{2}{|l|}{ ASET NETO TANPA PEMBATASAN } \\
\hline \multicolumn{2}{|l|}{ DARI } \\
\hline \multicolumn{2}{|l|}{ PEMBERI SUMBER DAYA } \\
\hline Saldo Awal & Rp $\quad 43.733 .673 .959$ \\
\hline Surplus (defisit) tahun berjalan & Rp (9.252.730.300) \\
\hline Saldo Akhir & $\underline{\operatorname{Rp}} \quad \underline{34.480 .943 .659}$ \\
\hline \multicolumn{2}{|l|}{ Penghasilan Komprehensif Lain } \\
\hline \multicolumn{2}{|l|}{ Saldo Awal } \\
\hline \multicolumn{2}{|c|}{ Penghasilan komprehensif tahun berjalan***) } \\
\hline Saldo Akhir & $\mathbf{R p}$ \\
\hline TOTAL ASET NETO & Rp $\quad 34.480 .943 .659$ \\
\hline
\end{tabular}

\section{Laporan Posisi Keuangan}

Laporan keuangan adalah laporan yang menyajikan informasi mengenai aktiva, kewajiban, dan aktiva bersih. Berikut Laporan posisi keuangan Masjid Baitul Makmur: Tabel 4. Laporan Posisi Keuangan Masjid Baitul Makmur Tahun 2020

\begin{tabular}{|c|c|c|c|}
\hline \multicolumn{4}{|l|}{$\overline{\text { ASET }}$} \\
\hline \multicolumn{4}{|l|}{ Aset Lancar } \\
\hline Kas & $\mathrm{Rp}$ & 129.598 .550 & \\
\hline Kas di Bank & $\mathrm{Rp}$ & 107.286 .959 & \\
\hline Perlengkapan & $\mathrm{Rp}$ & 710.000 & \\
\hline Total Aset Lancar & & $237 . \overline{595.509}$ & \\
\hline \multicolumn{4}{|l|}{ Aset Tidak Lancar } \\
\hline Tanah & $\mathrm{Rp}$ & 34.107 .750 .000 & \\
\hline Bangunan & $\mathrm{Rp}$ & 9.146 .250 .000 & \\
\hline Akumulasi Penyusutan Bangunan & $\mathrm{Rp}$ & $(9.146 .250 .000)$ & \\
\hline Peralatan & $\mathrm{Rp}$ & 373.078 .600 & \\
\hline Akumulasi Penyusutan Peralatan & $\underline{\mathrm{Rp}}$ & $(237.480 .450)$ & \\
\hline Total Aset Tidak Lancar & $\mathrm{Rp}$ & 34.243 .348 .150 & \\
\hline TOTAL ASET & & & Rp 34.480.943.659 \\
\hline \multicolumn{4}{|l|}{ ASET NETO } \\
\hline \multicolumn{4}{|c|}{$\begin{array}{l}\text { Tanpa pembatasan (without restrictions) } \\
\text { dari } \\
\text { pemberi sumber daya }\end{array}$} \\
\hline Surplus akumulasian & $\mathrm{Rp}$ & 34.480.943.659 & \\
\hline Penghasilan komprehensif lain*) & $\underline{\mathrm{Rp}}$ & & \\
\hline Total Aset Neto & $\underline{\underline{\mathrm{Rp}}}$ & 34.480 .943 .659 & \\
\hline TOTAL ASET NETO & & & Rp 34.480.943.659 \\
\hline
\end{tabular}


dibatasi oleh laporan perubahan aktiva bersih. Dengan ini diperoleh total aset bersih Rp 34.480.943.659.

\section{Laporan Arus Kas}

Laporan arus kas merupakan laporan yang menyajikan informasi tentang penerimaan dan pengeluaran kas dan setara kas pada suatu periode. Dalam laporan arus kas Masjid Baitul Makmur, laporan arus kas disajikan dalam dua jenis aktivitas, yaitu aktivitas operasi dan aktivitas investasi.

Adapun laporan arus kas Masjid Baitul Makmur yang telah penulis susun, yaitu:

Tabel 5. Laporan Arus Kas Masjid Baitul Makmur Tahun 2020

\begin{tabular}{|c|c|}
\hline AKTIVITAS OPERASI & \\
\hline Kas dari sumbangan & Rp 183.351 .800 \\
\hline Kas yang dibayarkan kepada karyawan & $\operatorname{Rp} \quad(45.900 .000)$ \\
\hline Kas yang dibayarkan untuk beban operasional & $(6.130 .650)$ \\
\hline Kas yang dibayarkan untuk pembelian perlengkapan & $\underline{\mathrm{Rp}} \quad(1.031 .000)$ \\
\hline Kas neto dari aktivitas operasi & $\operatorname{Rp} 130.290 .150$ \\
\hline AKTIVITAS INVESTASI & \\
\hline Pembelian peralatan & $(691.600)$ \\
\hline Kas neto yang digunakan untuk aktivitas investasi & $(691.600)$ \\
\hline KENAIKAN (PENURUNAN) NETO KAS DAN & \\
\hline SETARA KAS & Rp $\quad 129.598 .550$ \\
\hline KAS DAN SETARA KAS PADA AWAL PERIODE & $\underline{\mathrm{Rp}} \quad \underline{107,286,959}$ \\
\hline KAS DAN SETARA KAS PADA AKHIR PERIODE & $\underline{\underline{R p}} \underline{\underline{236.885 .509}}$ \\
\hline
\end{tabular}

Pada aktivitas operasi, terdapat kas dari sumbangan, yang berasal dari pendapatan infaq pada akun kas di buku besar sebesar Rp 183.351.800, kas yang dibayarkan kepada karyawan sebesar Rp 45.900.000, kas yang dibayarkan untuk beban operasional sebesar Rp 6.130.650 yang dimana saldo tersebut berasal dari jumlah pembayaran listrik, telepon, dan air sebesar Rp 745.650, pengeluaran untuk biaya rumah tangga seperti pembelian konsumsi untuk rapat sebesar Rp 100.000, pengeluaran untuk biaya peribadatan dan dakwah sebesar $\mathrm{Rp}$ 3.905.000, dan pengeluaran untuk pemeliharaan dan kebersihan masjid sebesar Rp 1.380.000. Sedangkan, kas yang dibayarkan untuk pembelian perlengkapan sebesar Rp1.031.000 berasal dari jumlah pembelian pigura struktur masjid sebesar Rp710.000 dan pembelian ATK dan lain-lain sebesar Rp321.000. Pada aktivitas investasi, terdapat pembelian peralatan pada tahun 2020 ini sebesar Rp 691.600. Total aktivitas operasi dan aktivitas investasi adalah peningkatan (penurunan) bersih kas dan setara kas Rp 129.598.550, yang saldonya akan sama dengan saldo akun kas di buku besar. Kemudian, hasil penambahan (penurunan) bersih kas dan setara kas tersebut ditambahkan ke saldo kas dan setara kas, dalam hal ini ditambah dengan saldo kas awal bank sebesar Rp 107.286.959 dan menghasilkan saldo kas dan setara kas pada akhir periode sebesar Rp 236.885.509. 


\section{Catatan Atas Laporan Keuangan}

Setelah melakukan penyusunan laporan laba rugi komprehensif, laporan perubahan aktiva bersih, laporan posisi keuangan dan laporan arus kas, langkah selanjutnya adalah membuat catatan atas laporan keuangan Masjid Baitul Makmur. Tujuan dari catatan atas laporan keuangan adalah untuk memberikan informasi rinci tambahan yang tidak termasuk dalam laporan keuangan.

\section{SIMPULAN}

Berdasarkan hasil dari penelitian yang sudah dilakukan, dapat disimpulkan bahwa Masjid Baitul Makmur Situbondo belum menyusun laporan keuangan sesuai dengan ISAK No. 35. Masjid hanya membuat Buku Kas Infaq Takmir Masjid Baitul Makmur dan Laporan Keuangan Bulanan yang mencatat transaksi pemasukan dan pengeluaran saja. dan Langkah yang dilakukan agar laporan keuangan Masjid Baitul Makmur sesuai dengan ISAK 35 adalah mengidentifikasi transaksi, membuat jurnal umum, mem-posting ke buku besar, membuat neraca saldo sebelum penyesuaian, membuat jurnal penyesuaian, membuat neraca saldo setelah penyesuaian, penyusunan laporan keuangan, jurnal penutup, dan neraca saldo setelah penutup. dan Hasil akhir dari proses akuntansi tersebut berupa laporan posisi keuangan, laporan penghasilan komprehensif, laporan perubahan aset neto, laporan arus kas, dan catatan atas laporan keuangan. Rekonstruksi Laporan Keuangan Masjid Baitul Makmur berdasarkan ISAK 35 menunjukkan bahwa Masjid Baitul Makmur memiliki antara lain Kas di Bank sebesar Rp 107.286.959 Aktiva Tetap sebesar Rp 43.626.387.000 dan Penghasilan Komprehensif sebesar (Rp 9.252.730.300).

Berdasarkan penelitian yang dilakukan, penelitian ini memiliki keterbatasan yaitu hanya studi kasus masjid yang menyajikan penyusunan laporan keuangan berbasis atau berdasarkan ISAK 35. Penelitian lebih lanjut dapat disusun berdasarkan ISAK 35, mengadopsi objek lain, seperti yayasan, organisasi kesehatan masyarakat, dll, atau dengan menganalisis penerapan ISAK 35.

\section{DAFTAR RUJUKAN}

Al-atqiyah, M. B., \& Al-atqiyah, M. B. (2021). Penerapan ISAK no. 35 tentang penyajian laporan keuangan entitas berorientasi nonlaba pada masjid besar al-atqiyah kecamatan moyo utara kabupaten sumbawa. 3(2), 63-75.

Andarsari, P. R. (2017). Laporan Keuangan Organisasi Nirlaba (Lembaga Masjid). Ekonika: Jurnal Ekonomi Universitas Kediri, 1(2), 143-152.

Ariyanti, R., \& Soraya, L. T. (2020). Analisis Penerapan Psak No. 45 Tentang Pelaporan Keuangan Organisasi Nirlaba Pada Utd Kabupaten Pekalongan. Jurnal Litbang Kota ..., 18(45), 56-67.

Dinanti, A., \& Nugraha, G. A. (2018). Pelaporan Keuangan Organisasi Nirlaba. Jurnal Ekonomi, Bisnis, Dan Akuntansi (JEBA), 20(1), 1-8.

Diviana, S., Putra Ananto, R., Andriani, W., Putra, R., Yentifa, A., Zahara, \& Siswanto, A. (2020). Penyajian Laporan Keuangan Entitas Berorientasi Nonlaba 
Berdasarkan Isak 35 Pada Masjid Baitul Haadi. Akuntansi Dan Manajemen, 15(2), 113-132.

Kusuma. (2020). Analisis Penyusunan Laporan Keuangan Gereja Stasi St. Petrus Kwala Berdasarkan ISAK 35. Convention Center Di Kota Tegal, 4(80), 4.

Lasfita, N., \& Muslimin. (2020). Penerapan ISAK No. 35 Pada Organisasi Keagamaan Masjid Al- Mabrur Sukolilo Surabaya. Jurnal Sosial Ekonomi Dan Politik, 1(35), 65-68.

Muhasaba, E. L., \& Akuntansi, J. (2020). Penyusunan Laporan Keuangan Masjid Berdasarkan PSAK 45. 11(2), 114-122.

Nelva Susanti Sri. (2020). Analisis Penerapan ISAK No. 35 Terhadap Laporan Keuangan Pada Yayasan Mts Al-Manar Kecamatan Pujud Kabupaten Rokan Hilir Periode 2018-2019. In Skripsi Uin Suska Riau (Issue 35).

Pamulang, U. (2020). Analisis Penerapan PSAK No. 45 Tentang Pelaporan Keuangan Entitas Nirlaba Pada Panti Asuhan Al-Husna Bukit Pamulang Indah. 4(45), 2939.

Raco, J. (2018). Metode penelitian kualitatif: jenis, karakteristik dan keunggulannya.

Shoimah, I., Wardayati, S. M., \& Sayekti, Y. (2021). Adaptasi Laporan Keuangan Pada Entitas Nonlaba Berdasarkan Isak 35 (Studi Kasus pada Universitas Ibrahimy Sukorejo Situbondo). Jurnal Akuntansi Dan Pajak, 21(02), 243-259.

Slamet Sugiri dan Bogat Agus Riyono. (2001). PPSAK 13 Pencabutan PSAK 45: Pelaporan Keuangan Entitas Nirlaba. 88.

Thullab, Y. N. (2014). Pertanggungjawaban Keuangan Pada Yayasan Nazhatut Thullab. 3(11).

Wijaya, H. (2013). Metode Penelitian. E-Modul, August 2013, 1-8. 